\title{
Study on Regional Culture Consumption Level and Its Affecting Factors-On Basis of 31 Provinces' Data in China
}

\author{
Bo Wang1,2 \\ ${ }^{1}$ China Construction Bank Postdoctoral Work Station, Beijing, China \\ ${ }^{2}$ Tsinghua University Postdoctoral Work Station, Beijing, China \\ Email: wangbo1985113@163.com
}

How to cite this paper: Wang, B. (2018). Study on Regional Culture Consumption Level and Its Affecting Factors-On Basis of 31 Provinces' Data in China. Advances in Applied Sociology, 8, 350-358. https://doi.org/10.4236/aasoci.2018.84020

Received: February 26, 2018

Accepted: April 27, 2018

Published: April 30, 2018

Copyright $\odot 2018$ by author and Scientific Research Publishing Inc. This work is licensed under the Creative Commons Attribution International License (CC BY 4.0).

http://creativecommons.org/licenses/by/4.0/

\begin{abstract}
Cultural consumption plays a positive role on economic development and social development; it also is the key factor to the improvement of culture industry. Taken the regional culture consumption as the subject, this paper emphasizes on discussing the environmental influencing factors of the regional culture consumption and finds the mechanism that how these factors work using the quantile regression model on the Basis of 31 Provinces' Data in China ${ }^{1}$.
\end{abstract}

\section{Keywords}

Culture Consumption, Quantile Regression Model, Regional Disparity, Affecting Factors Model

\section{Introduction}

With the rapid development of economy and society, the overall income and consumption level of the residents have been continuously improved and the cultural demand of residents has been showing an increasing trend. According to Maslow's hierarchy of needs theory, the spiritual demand is the relatively high-level demand of human needs, world development experience history also indicated that the proportion of material consumption expenditure will be further reduced and cultural products began to increase after the material demands such as food, clothing and shelter are fulfilled.

${ }^{1}$ China includes 34 provincial administrative regions in total, however the statistical caliber of special administrative regions (Hong Kong, Macau) and Taiwan province are different from the statistical caliber of other 31 provincial administrative regions, and in this study we use the data of 31 provinces in China. 
Cultural consumption has significant effect on economic and social development. Firstly, cultural consumption plays a positive role on economic development. Cultural consumption is an important part of residents' consumption, at the beginning period of the market economy development due to the low level of people's material life, the cultural demand is not very strong and the economic effect of cultural consumption is not outstanding, but along with improvement of living standards, cultural consumption grows rapidly, the economic value of cultural consumption has already showed up. Cultural consumption level can not only promote the residents' consumption in developing countries, but also promote the residents' consumption structure optimization, thus promotes the quality and efficiency of economy growth. Secondly, cultural consumption plays an important role in cultural production. Production and consumption depend on each other and promote each other; cultural consumption has important effect on cultural production. Cultural consumption as the end of the cultural production chain is the endogenous power of cultural production. Therefore, improving the level of cultural consumption can directly promote the development of cultural industry, and break through the bottleneck of cultural development. Thirdly, cultural consumption plays a virtual role on social development. Cultural consumption meets people's spiritual needs, raising the overall culture level of the people, enhancing the degree of social civilization and promoting social harmony and stability.

According to the historical experience of developed countries, if the per capita GDP reaches the level of $\$ 5000$, cultural consumption will show an explosive growth trend ${ }^{2}$. The biggest developing country-China's per capita GDP was almost $\$ 9000$ in 2016, the residents' culture consumption has showed a trend of growth but did not show explosive grow trend, related studies have shown that under the same level of the GDP per capita, China's cultural consumption is only $30 \%$ of that in the developed countries, the overall cultural consumption level of residents is still very low and the regional disparity is very obvious ${ }^{3}$. Thus in this paper, we will have a system analysis on the influence factors of the consumption level and find the way to enhancing the level of culture consumption and promoting the overall culture competition power.

\section{Literature Review of Cultural Consumption}

The initial stage of modern consumption theory can be traced back to "absolute income hypothesis" put forward by Keynes (1936), this theory preliminarily established the relationship between consumption and income. The study of neoclassical economics shows that the main factors that influence demand include the price of commodities, income and other commodity' price. Bourdieu (1984) and Veblen (1899) believed that cultural consumption was the "conspicuous

${ }^{2}$ Hollis \& Syrquin (1975) Patterns of development (1950-1970) [M]. New York: Oxford University Press for the World Bank, 30.

${ }^{3}$ The data source is China Statistical Yearbook (2017), China cultural consumption index (2016). 
consumption" of the leisure class at the beginning of the cultural consumption study. The differences of cultural consumption was able to distinguishing the class people belonged to, when the people have more personal assets there were more "conspicuous consumption". The difference between classes is closely related to personal income, so this view identified the close relationship between cultural consumption and income from another aspect. Hollis \& Syrquin (1975) did an empirical research on the relationship between cultural consumption level and the per capita GDP using more than 100 countries' data, the empirical research result was when the per capita GDP increased from $\$ 3000$ to $\$ 5000$, the proportion of the cultural consumption spending occupies total consumer spending rose from $23 \%$ to $35 \%$, the rapid growth cultural consumption level was along with the rapid growth of economic development. The improvement of income level means that consumers have stronger purchasing power; this offers the possibility that utility maximization consumer breakthrough the existing consumption level constraints to a higher level of consumption. Goldthorpe (2007), Lange \& Meier (2009), these researchers found that level of education, gender, age have a joint effect on consumer culture spending based on US residents. Paulo \& Barros (2005) build individual consumers dynamic specification model under the constant consumption preference, the study found that income has positive effect on cultural consumption, but demand income elasticity is low, the cultural product prices have negative effects on cultural consumption. Katsuura (2012) used the market transformation model with the data that Japanese residents monthly culture consumption spending data, in this study it was the first time that the economic cycle cultural was considered in culture consumption field. Wang (2016) analyzed the relationship between growth of per capita output, income, education level, total consumption, savings and cultural consumption in China between 2001 and 2008. The conclusion of the study is that the growth of per capita savings plays a negative role on the growth of cultural consumption; the growth of per capita income and per capita consumption growth have a positive impact on cultural consumption. Zhou, Gu, \& Lu (2013) establish the cultural consumption function using the ELES model and empirically examines the influencing factors of cultural consumption. The study finds that income, total consumption expenditure and cultural consumption are positively correlated, urban and rural differences have a significant impact on cultural consumption. Wen, Zhang, \& Li (2017) analyzes rural residents' cultural consumption expenditure, and selects the gender, age, nationality, education level, family per capita income as variables, using the corresponding analysis model to explore the influencing factors of rural residents' cultural consumption expenditure based on the survey data of 4380 rural residents' cultural life in 2013 in 15 provinces of China. This study indicated that Age, education level and family per capita annual income have significant influence on the expenditure of cultural consumption of rural residents. The cultural expenditure of rural residents will increase with the increase of education level and the per capita annual income of the family. With the growth of age, rural residents will reduce cultural consump- 
tion, but their cultural consumption will rise again when they are over 60 .

From the existing research literature it is not hard to find that cultural consumption research mainly focus on the theoretical research, the current empirical study about cultural consumption influencing factors did not mention that how different cultural consumption level was affected by the different environmental impact factors. So in this paper, we conclude the cultural consumption theory on the basis of previous literature and summarize environmental affecting factors, using panel quintile regression model based on China's 31 provinces cultural consumption data in 2009-2015 to analyze how different level of residents consumption is affected by the environmental impact factors and conclude its mechanism of action.

\section{The Influencing Factors Analysis of the Cultural Consumption Level Based on the Quantile Panel Regression}

According to the China statistical data, per capita cultural spending of residents in China showed a rising trend year by year, the national per capita cultural spending of residents in 2016 was twice as much as the amount in 2010, the residents' culture consumption grew rapidly. Urban culture cultural and educational entertainment consumer spending has increased dramatically, per capita urban cultural and educational entertainment spending in 2010 rose from 1627.6 Yuan to 2637.6 Yuan in 2016; per capita cultural spending of rural residents rose from 366.7 Yuan in 2010 to 1070.3 Yuan 2016, the average annual growth rate of rural residents spending' on culture is more faster than urban residents, the statistic data also showed that China's cultural consumption gap between urban and rural is very obvious ${ }^{4}$. From regional distribution of cultural consumption level, the areas with higher cultural consumption per capita are mainly concentrated in the east part of China, such as Shanghai, Beijing, Jiangsu, Zhejiang, Guangzhou province; the areas with lower cultural consumption per capita are mainly concentrated in western part of China. So in this paper we will analyze the influence factors mechanism of residents' culture consumption level based on the culture consumption data of 31 provinces in China. Based on the previous research results and the actual situation of Chinese cultural consumption, five core cultural consumption affecting factors were selected as followed:

1) Resident's income level

According to the income level theory income is the material basis of cultural consumption which also is one of the most important influence factors to cultural consumption. Maslow's hierarchy of needs theory indicated that people often have different consumption style according to the different levels of need, spiritual demand is enjoyable and developed demand which generate on the basis of the material demand was met (Yan \& Lei, 2016). The consumption of culture product will ascend accompanied by income level' ascension trend, because

${ }^{4}$ The data source is China Statistical Yearbook (2013-2017). 
as people's income ascension people will generate more needs of spiritual after they meet the basic survival needs such as food, clothing, sheltered. In this paper we use per capita disposable income (Yuan/person) to indicate the income level of urban residents.

2) Government input level

Government investment in culture represents that the degree of importance that local government attaches to the cultural production and consumption, government's cultural input which have a motivate, support, guidance, integrate function to cultural consumption which can create a good cultural consumption environment, thereby promoting the ascension residents' culture consumption level. Public cultural product consumption is also an important part of cultural consumption, the government can promote the cultural consumption level through increasing investment on public cultural services system and providing more public goods, so the government investment in culture can further release the residents' cultural needs. This paper we adopts the per capita government cultural and entertainment financial appropriation as a measure of government culture input level.

3) Urbanization level

The city is the center of regional' development and the city culture industry development have stronger resource accumulation and radiation ability compared to the countryside (Hu \& Tian, 2015). No matter culture industry development or public culture service, the city developed relatively more mature and it can provide more cultural products and better public cultural service. At the same time, urbanization can transform some rural population into urban population, which is conducive to the formation of cultural consumption habits and release more people' cultural consumption demand. This paper uses urbanization to measure urbanization.

4) Literacy level

The difference between cultural consumption and ordinary commodity consumption is consumption of cultural products meets the demand of the human spirit, the value of cultural products reflected through meeting the needs of the consumer' mental enjoyment and development, so consumers with different education level have different culture consumption concept. Generally speaking, when consumer literacy level is higher, personal comprehensive development desire will be more intense, the consumer demand and willingness for cultural product is higher (Tian \& Wang, 2016). Cultural demand is a self-reinforcing function demand that means consumers with high education level they consume more culture products and service to build the consume capital which will prompt the consumers have more cultural demand. Besides some cultural products' consumption requires knowledge accumulation. The consume area of well-educated consumers is relatively more extensive and more receptive to new cultural consumption hotspots. The overall improvement of the residents' literacy level can theoretically drive the improvement of cultural consumption level. In this paper the level of residents' literacy level is reflected by residents' average education years. 
5) Social aging level

The trend of aging society is becoming more and more obvious due to medical advances and slow birth rate growth; the cultural consumption of the elderly population is getting more and more attention. It is a special group in general with higher disposable income, leisure time, which is an important force in cultural consumption, however as there is no specific cultural products segmentation for elderly people on the whole, ageing population' cultural consumption is not very high. Therefore, the aging level has a reduplicate effect on cultural consumption (Zhao \& Yao, 2016). This paper adopts the proportion of the elderly population and the dependency ratio to represent the social aging level.

The quantile regression can analyze the different variables effects at different levels compared to traditional least-squares regression (Koenker, 2004); traditional ordinary least-square regression model only can fit one curve with interpreted and explain variables as quantile regression can fit various curves according to the researchers' study. In this paper, we use the quantile regression model to show a more comprehensive characterization that how different cultural consumption level is affected by the environmental factors. In addition, the quantile regression model is less affected by the abnormal value data, so the quantile regression model is more stable than the traditional regression model (Graham et al., 2015). In order to consider the time factor and individual differences in the model, this paper uses the panel data to make a more thorough analysis of data. The basic expression is:

$$
Y_{i t}\left(\tau_{j} \mid x_{i t}, \alpha_{i}\right)=X_{i t}^{T} \beta\left(\tau_{j}\right)+\alpha_{i}
$$

Taking into account the individual effect, the penalty item is introduced to replace the original Gaussian penalty and the estimated value of the panel quantile regression parameter is solved by the penalty function.

$$
\min \sum_{k=1}^{q} \sum_{i=1}^{n} \sum_{j=1}^{t} w_{k} \rho\left(\tau_{k}\right)\left(Y_{i t}-a_{i}-X_{i t} \beta\left(\tau_{k}\right)+\lambda \sum_{i=1}^{n}\left|a_{i}\right|\right)
$$

This paper use the per capita cultural and entertainment expenditure of residents as a measure of the residents' cultural consumption in 2009-2015, and cultural consumption level affecting factors model is:

$$
\begin{aligned}
\text { CONSUME }_{i t}= & \alpha_{i t}+\beta_{1} I_{N C O M E_{i t}+\beta_{2} \text { CIR }_{i t}+\beta_{3} A G D P_{i t}} \\
& +\beta_{4} G O V_{i t}+\beta_{5} E_{i t}+\beta_{6} O L D_{i t}+\beta_{7} \text { FOS }_{i t}+\varepsilon_{i t}
\end{aligned}
$$

Among that, INCOME represents residents per capita disposable income, $C I R$ represents urbanization rate, $A G D P$ represents $G D P$ per capita, $G O V$ represents cultural entertainment funding, $E D U$ represents residents' per capita education year, $O L D$ on behalf of aging population proportion (more than 60 years old), FOS represent bring-up ratio.

The analysis results based on quantile panel regression computation showed that the urban per capita disposable income, urbanization rate and residents' per capita year of the education have the positive influence on cultural consumption, among the positive factors urban per capita disposable income is the most im- 
portant factor to culture consumption. Per capita $G D P$, cultural and recreational financial allocation, aging population and dependency ratio play a different role in different levels of cultural consumption. From the analysis results of general panel regression, only the per capita disposable income of urban residents has a significant impact on the cultural consumption level (Table 1).

And based on a quantile panel regression, we can get more detailed and more comprehensive analysis, quantile panel regression results are as followed.

At $10 \%$ quantile level, urban per capita disposable income, urbanization rate has significant impact on cultural consumption. When other conditions do not change, per capita disposable income of urban residents increases by $1 \%$, the cultural consumption increases by $0.5638 \%$; urbanization rate increases by $1 \%$, the cultural consumption increases by $0.2823 \%$.

At $25 \%$ quantile level the most important influence factor that affects culture consumption of urban residents is residents' disposable income, at this level urban resident per capita disposable income has more significant impact on cultural consumption compared to cultural consumption at $10 \%$ quantile level. At $50 \%$ quantile level, urban per capita disposable income and per capita GDP have biggest impact on cultural consumption and urban per capita disposable income has greater influence compared to low consumption level.

Table 1. Cultural consumption level influencing factors regression results.

\begin{tabular}{|c|c|c|c|c|c|c|}
\hline \multirow{2}{*}{ Variables } & Ordinary & \multirow{2}{*}{ Q10 } & \multirow{2}{*}{ Q25 } & \multirow{2}{*}{ Q50 } & \multirow{2}{*}{ Q75 } & \multirow{2}{*}{ Q90 } \\
\hline & Panel Model & & & & & \\
\hline \multirow{2}{*}{ Intercept } & \multirow{2}{*}{ - } & $-0.4331^{* * *}$ & $-0.23402^{\star * *}$ & 0.0186 & $0.2843^{* * *}$ & 0.4748 \\
\hline & & $(-8.3727)$ & $(-4.2816)$ & -0.2381 & -4.8085 & -18.1812 \\
\hline \multirow{2}{*}{ INCOME } & $0.2024^{\star}$ & $0.5638^{* * *}$ & $0.7402^{\star * *}$ & $0.89725^{\star * *}$ & $0.8715^{\star * *}$ & $0.9412^{* * *}$ \\
\hline & $(2.0488)$ & -7.4731 & -9.2903 & -6.5509 & -6.54768 & -8.6688 \\
\hline \multirow{2}{*}{$C I R$} & 0.0941 & $0.2823^{\star *}$ & 0.1825 & 0.1277 & $0.2584^{\star \star}$ & $0.22680^{* *}$ \\
\hline & -0.3565 & -3.0441 & -1.8827 & -0.1089 & -2.88299 & -2.7529 \\
\hline \multirow{2}{*}{$A G D P$} & 0.0229 & 0.0328 & -0.0473 & $-0.0840^{\star}$ & -0.0473 & 0.0034 \\
\hline & -0.3647 & -0.5101 & $(-0.7335)$ & $(-2.1893)$ & $(-0.8290)$ & -0.0568 \\
\hline \multirow{2}{*}{$G O V$} & 0.0025 & -0.0536 & -0.06003 & -0.0258 & 0.03388 & -0.0041 \\
\hline & -0.0908 & $(-1.2239)$ & $(-0.58961)$ & $(-0.2940)$ & -0.2322 & $(-0.0191)$ \\
\hline \multirow{2}{*}{$E D U$} & 0.0061 & 0.0063 & 0.01391 & 0.0251 & 0.0377 & 0.0487 \\
\hline & -1.168 & -0.0573 & -0.122 & $(0.0528)$ & -0.6761 & -0.5842 \\
\hline \multirow{2}{*}{$O L D$} & 0.0169 & 0.02430 & 0.0066 & 0.0079 & -0.0047 & -0.03803 \\
\hline & -0.5405 & $(0.3978)$ & -0.1865 & -0.2019 & $(-0.0983)$ & $(1.06474)$ \\
\hline \multirow{2}{*}{ FOS } & -0.0901 & 0.02401 & 0.04567 & -0.01232 & 0.02598 & $0.0615^{\star}$ \\
\hline & $(-1.3124)$ & -0.5971 & -0.8331 & $(-0.2949)$ & -0.6121 & -2.30102 \\
\hline
\end{tabular}

*** represent $P<0.001,{ }^{* *}$ represent $P<0.01,{ }^{*}$ represent $P<0.05$. The data source is China cultural year book (2010-2016); China regional economic yearbook (2010-2016); China statistical yearbook (2010-2016). 
At $75 \%$ quantile level urban per capita disposable income and the influence of urbanization level for cultural consumption show a further increase impact on culture consumption, the influence of other factors were not significant.

At $90 \%$ level, urban per capita disposable income, urbanization rate and the dependency ratio have a significant impact on cultural consumption levels, urban per capita disposable income and urbanization rate is still the core influence factors.

From the trend of the environmental influencing factors change, per capita disposable income has a greater influence on culture consumption with the improvement of quantile per capita disposable income, from $10 \%$ quantile up to $90 \%$ quantile per capita disposable income coefficient grow from 0.2024 up to 0.9412 , that means along with the growth of residents' per capita disposable income, cultural consumption level of residents continue to increase. This analysis result indicates that residents with the low cultural consumption that the main demand is material needs, the level of income do not have a big impact on the cultural consumption, the inhabitants of high cultural consumption level will greatly increase the culture consumption when the disposable income increases.

With the improvement of cultural consumption quantiles, the effecting factor that over 60 elderly population proportion' impact changes from positive to negative which indicated that there is more cultural consumption time for the aging population, at the low level of culture consumption as population aging degree play a positive role on culture consumption. However, culture products and service for elderly population are not fully developed, thus as the consumption increase the aging population level play a negative role. With the level of cultural consumption increase, the impact of education years on cultural consumption has also increased.

\section{Conclusion}

This paper analyzes the regional culture consumption level and its affecting factors' mechanism using the panel quantile regression on basis of 31 Provinces' data in China. From the analysis results of statistical model, the mechanism of environmental factors to regional cultural consumption level at different quantile is different, however on the whole the residents per capita disposable income, per capita $G D P$, and urbanization rate have a important influence on the cultural consumption level.

\section{References}

Bourdieu, P. (1984). Distinction: A Social Critique of the Judgment of Taste. London: Routledge.

Goldthorpe, J. (2007). On Sociology (2nd ed.). Stanford: Stanford University Press.

Graham, B. S., Hahn, J., Poirier, A., \& Powell, J. L. (2015). Quantile Regression with Panel Data. NBER Working Paper No. 21034. Cambridge, MA: NBER. https://doi.org/10.3386/w21034 
Hollis, C., \& Syrquin, M. (1975). Patterns of Development (1950-1970). New York: Oxford University Press for the World Bank.

Hu, N. W., \& Tian, Z. F. (2015). Research on Cultural Consumption and Regional Difference in China. Economic Problems, No. 7, 1-6.

Katsuura, M. (2012). Lead-Lag Relationship between Household Cultural Expenditures and Business Cycles. Journal of Cultural Economics, 36, 49-65. https://doi.org/10.1007/s10824-011-9155-1

Keynes, J. M. (1936). The General Theory of Employment, Interest, and Money. Beijing: China Social Sciences Press.

Koenker, R. (2004). Quantile Regression for Longitudinal Data. Journal of Multivariate Analysis, No.1, 74-89. https://doi.org/10.1016/j.jmva.2004.05.006

Lange, H., \& Meier, L. (2009). The New Middle Classes Globalizing Lifestyles, Consumerism and Environmental Concern. New York, NY: Springer.

Paulo, B., \& Barros, C. (2005). Learning-by-Consuming and the Dynamics of the Demand and Prices of Cultural Goods. Journal of Cultural Economics, 29, 83-106. https://doi.org/10.1007/s10824-005-1748-0

Tian, H., \& Wang, H. Y. (2016). The Regional Differences of Cultural Consumption of Chinese Urban and Rural Residents. Journal of Northeast Normal University (Philosophy and Social Sciences), No.3, 25-34.

Veblen, T. (1899). The Theory of the Leisure Class. New York: MacMillan.

Wang, Y. N. (2016). Annual Evaluation Report of Cultural Consumption Demand. Beijing: Social Sciences Academic Press.

Wen, L. J., Zhang, J., \& Li, S. D. (2017). Rural Residents' Cultural Consumption Expenditure and the Influencing Factors: Based on Individual Factors and Correspondence Analysis Model. Journal of Hunan Agricultural University (Social Sciences), 18, 1-6.

Yan, C. L., \& Lei, X. J. (2016). Analysis of Impact of Chinese Household's Culture Consumption. Journal of University of South China (Social Science Edition), 17, 48-53.

Zhao, G. Q., \& Yao, Q. S. (2016). Age Structure and Household Consumption: Evidence from China's Provincial Panel Data. The Journal of Quantitative Economics, 7, 28-42.

Zhou, L., Gu, J., \& Lu, C. P. (2013). Cultural Consumption Analysis Based on ELES Model. Modern Management Science, No. 8, 12-15. 